\title{
PERBEDAAN TINGKAT DEFISIT NEUROLOGIS PADA STROKE ISKEMIK LESI HEMISFER KIRI DAN KANAN
}

\author{
THE DIFFERENCE OF NEUROLOGICAL DEFICIT LEVELS IN THE ISCHEMIC \\ STROKE LEFT AND RIGHT HEMISPHERELESIONS
}

\author{
Muhamad Prayoga, Ani Rusnani Fibriani, Nining Lestari \\ Fakultas Kedokteran Universitas Muhammadiyah Surakarta \\ Korespondensi, dr. Ning Lestari, Email: dr.nining.lestari.nl@gmail.com
}

\begin{abstract}
ABSTRAK
Stroke merupakan penyebab kematian terbanyak kedua di negara maju dan ketiga terbanyak di negara berkembang. Stroke akan menyebabkan defisit neurologis yang berbeda-beda tergantung kepada daerah otak yang terganggu.Terdapat perbedaan anatomi dan fisiologi dari hemisfer kiri dan kanan sehingga apabila terjadi kerusakan maka akan terjadi perbedaan outcome pada masing-masing hemisfer. Penelitian ini bersifat analitik observasional dengan pendekatan cross sectional. Penelitian dilaksanakan di Bagian Rekam Medik RSX Surakarta pada bulan November-Desember 2015. Pengambilan sampel dilakukan dengan teknik purposive sampling dengan menggunakan 58 sampel penderita stroke iskemik, terdiri atas 29 sampel lesi hemisfer kiri dan 29 sampel lesi hemisfer kanan. Pada penelitian ini diperoleh rerata NIHSS Stroke iskemik lesi hemisfer kiri sebesar 11,9655 dengan simpang baku ( \pm 3.417) dan stroke iskemik lesi hemisfer kanan sebesar 7,9655 dengan simpang baku ( \pm 2,211). Hasil uji statistik uji Mann Whitney nilai signifikansi $p=0,001(p<0,05)$. Berdasarkan penelitian ini, dapat disimpulkan bahwa terdapat perbedaan tingkat defisit neurologis pada stroke iskemik lesi hemisfer kiri dan kanan. Tingkat defisit neurologis lesi hemisfer kiri lebih tinggi dari pada lesi hemisfer kanan.
\end{abstract}

Kata kunci : stroke iskemiklesi hemisfer kiri dan kanan, NIHSS, defisit neurologis.

\section{ABSTRACT}

Stroke is the second largest cause of death in developed countries and the third largest in the developing countries. Stroke will cause various neurological deficit depending on damage area of the brain. Due to differences of anatomy and physiology of left and right hemisphere, damage on different hemisphere leads to defferentsoutcome. This research is an observational analytic with cross sectional approach. It is carried out in Medical Record Unit of X Hospital in November to December of 2015. The Sampling is conducted by purposive sampling technique choosing 58 samples of ischemic stroke patients that consist of 29 samples having left hemisphere lesion and 29 samples having right hemisphere lesions. The result of this study shows that mean NIHSS left hemisphere lesions are 11.9655 with standard deviation $( \pm 3.417)$ and left hemisphere lesions are 7,9655 with standard deviation \pm 2,211).The result of Mann Whitney testsignificant value is $p=0,001(p<0,05)$. Therefore, it can be concluded that neurological deficit level in the left ischemic stroke lesions is higher than right hemisphere lession.

Keywords : left and right hemisphere ischemic stroke, NIHSS, neurological deficit.

\section{PENDAHULUAN}

Stroke adalah penyakit fungsional otak fokal maupun global akut dengan gejala dan tanda sesuai bagian otak yang terkena, yang sebelumnya tanpa peringatan; dapat sembuh sempurna, sembuh dengan cacat, atau bahkan sampai berujung pada kematian; akibat gangguan aliran darah ke otak karena perdarahan ataupun non perdarahan (Junaidi, 2005). Tanda-tanda klinis pada penyakit stroke berkembang cepat dengan gejala yang berlangsung selama 24 jam atau lebih atau menyebabkan kematian, tanpa adanya penyebab lain yang jelas selain vaskuler (PERDOSSI, 2011).

Stroke iskemik pada dasarnya terjadi akibat kurangnya aliran darah ke otak. Pada keadaan 
normal aliran darah ke otak adalah $58 \mathrm{ml} / 100$ gr jaringan otak per menit. Bila hal ini turun sampai $18 \mathrm{ml} / 100$ gr jaringan otak setiap menit maka aktivitas listrik neuron terhenti tetapi struktur sel masih baik, penurunan aliran darah ini apabila semakin parah dapat menyebabkan jaringan otak mati dan dapat menyebabkan perubahan fungsional dan struktural otak yang irreversibel (Gofir, 2009).

Setiap tahun 15 juta orang didunia terkena penyakit stroke, 5 juta dari yang terkena meninggal dunia dan 5 juta lainnya mengalami kelumpuhan permanen (WHO, 2010). Di negara maju, stroke merupakan penyebab kematian ketiga setelah penyakit jantung dan kanker. Setiap tahun, hampir 700.000 orang Amerika mengalami stroke dan mengakibatkan hampir 150.000 kematian (Goldszmidt, 2013). Prevalensi stroke berdasarkan diagnosis dokter di Indonesia mengalami peningkatan dari 8,3\% (dari seluruh jumlah penduduk) pada tahun 2007 menjadi 12,1 $\%$ pada tahun 2013. Di provinsi Jawa Tengah, stroke juga mengalami peningkaan yang cukup menonjol yaitu 7,9\% (dari jumlah penduduk) pada tahun 2007 menjadi $12.2 \%$ pada tahun 2013. Berdasarkan data dari dinas kesehatan provinsi Jawa Tengah, penyakit jantung dan pembuluh darah merupakan penyakit dengan jumlah penderita paling tinggi di antara penyakit tidak menular (PTM) lainnya. Prevalensi stroke hemoragik di Jawa Tengah tahun 2012 adalah 0,07 lebih tinggi dari tahun $2011(0,03 \%)$ sedangkan prevalensi stroke iskemik pada tahun 2012 adalah sebesar 0,07 lebih rendah dibanding 2011 (0,09\%) dari 33.270.207 jiwa (Kemenkes RI, 2014).

Stroke jenis apapun akan menyebabkan defisit neurologis yang berbeda-beda tergantung kepada daerah otak yang terganggu aliran darahnya dan fungsi daerah otak yang mengalami iskemia tersebut. Gejala yang timbul dapat berupa hemiparesis, hemihipestesi, gangguan berbicara (afasia), bicara pelo, hemianopsia, gangguan fungsi intelektual dan lain-lain (Misbach, 2011). Riset menunjukkan bahwa anatomi dan histologi antara hemisfer kiri dan hemisfer kanan memiliki struktur yang berbeda. Perbedaan ini membuat adanya spesialisasi fungsi dari masing-masing hemisfer dan apabila terjadi kerusakan maka kerusakan yang ditimbulkannya juga akan menunjukkan dominansi yang berbeda pula (Pasiak, 2009).
Sampai saat ini terdapat banyak instrumen yang dapat digunakan untuk menilai status neurologis pasien stroke, diantaranya ialah skor Orgogozo, indeks Barthel, Modified Rankin Scale, Scandinavian Stroke Scale, dan National Institutes of Health Stroke Scale (NIHSS). NIHSS memiliki keunggulan karena penilaiannya meliputi beberapa aspek neurologis, yaitu : kesadaran, motorik, sensorik, dan fungsi luhur, lebih mudah serta lebih cepat untuk dilakukan, baik oleh neurolog maupun non neurolog, dapat memprediksi outcome pasien baik untuk jangka panjang maupun jangka pendek, dan saat ini merupakan instrumen yang sah digunakan di seluruh dunia untuk menilai derajat keparahan outcome pasien stroke (Napitupulu, 2011).

Menurut beberapa penelitian sebelumnya yang dilakukan oleh Lyden et al (2004), Legge et al (2006), Schellinger et al (2010), dan Hedna et al (2013) dalam penelitiannya menyebutkan bahwa defisit neurologis pada stroke iskemik lesi hemisfer kiri memiliki nilai lebih buruk dari pada stroke iskemik lesi hemisfer kanan, pengukuran tingkat defisit neurologis tersebut diukur menggunakan NIHSS. Berbeda dengan penelitianpenelitian diatas, pada penelitian yang dilakukan oleh Fink et al (2008) menyebutkan bahwa tidak ada perbedaan tingkat defisit neurologis antara lesi hemisfer kiri dan kanan yang diukur tingkat defisit neurologisnya menggunakan NIHSS.

Berdasarkan penelitian-penelitian sebelumnya mengenai perbedaan tingkat defisit neurologis pada pasien stroke iskemik dengan lesi hemisfer kiri dan kanan masih terdapat berbagai kontroversi, maka penulis terdorong untuk melakukan penelitian mengenai hal tersebut di RSUD Dr. Moewardi

\section{METODE}

Penelitian ini menggunakan desain observasional analitik dengan metode pendekatan cross sectional untuk mengetahui perbedaan tingkat defisit neurologis pada stroke iskemik lesi hemisfer kiri dan hemisfer kanan.Penelitian ini dilakukan di unit rekam medis RSUD Dr. Moewardi bulan Oktober-November 2015.

Populasi target penelitian ini adalah pasien stroke iskemik yang datang ke RSUD Dr. Moewardi yang memenuhi kriteria 
retriksi. Populasi aktualnya yaitu pasien stroke iskemik yang datang ke RSUD Dr. Moewardi pada tahun 2013-2014 yang memenuhi kriteria retriksi. Sampelpada penelitian ini adalah hasil pencuplikan dari populasi dengan pemilihan tidak berdasarkan peluang (non-probability sampling) menggunakan teknik Purposive Sampling, yaitu suatu teknik pemilihan sampel yang dipilih berdasarkan pertimbangan subyektif dan praktis, sehingga dapat memberikan informasi yang memadai untuk menjawab pertanyaan penelitian (Hadi, 2000).

Variabel yang diuji pada penelitian ini adalah tingkat defisit neurologis pada stroke iskemik lesi hemisfer kiri dan kanan.Stroke iskemik diukur menggunakan pengukuran CTScan (Gold standard) dibedakan atas lesi hemisfer kiri dan kanan sedangkan defisit neurologis diukur menggunakan kuisioner NIHSS yang memiliki 11 butir pertanyaan dengan hasil nilai 0-42.Penelitian ini menggunakan 29 sampel lesi hemisfer kiri dan 29 sampel lesi hemisfer kanan, masing-masing sampel diambil data dari instaasi rekam medik berupad ata usia, jenis kelamin, kadar gula darah sewaktu, tekanan darah, letak lesi, dan nilai NIHSS (National Institutes of Health Stroke Scale) pasien stroke iskemik RSUD Dr. Moewardi.

Data yang diperoleh dari hasil penelitian diolah dalam program SPSS 17.0 for windows. Analisis data menggunakan uji t tidak berpasangan atau uji Mann Whitney. Syarat dilakukannya Uji t tidak berpasangan adalah memiliki sebaran data yang normal, untuk mengetahuinya data hasil penelitian diuji menggunakan test normalitas Shapiro-wilk dilanjutkan uji Mann Whitney.

\section{HASIL DAN PEMBAHASAN}

\section{A. Karakteristik Subjek Penelitian}

Sampel yang digunakan pada penelitian ini menggunakan 58 sampel dengan ditribusi berdasarkan beberapa karakteristik sebagai berikut.

Tabel 1. Karakteristik Sampel Penelitian

\begin{tabular}{llcc}
\hline No & \multicolumn{1}{c}{ Variabel } & Jumlah & Persentase \\
\hline 1 & Usia & & \\
& $\leq 50$ tahun & 7 & $12 \%$ \\
& $>50$ tahun & 51 & $88 \%$ \\
2 & Jenis Kelamin & & \\
& Laki-laki & 35 & $60,3 \%$ \\
& Perempuan & 23 & $39,7 \%$ \\
3 & GDS & & \\
& $<200$ mm/dl & 27 & $46,6 \%$ \\
& $>200$ mm/dl & 31 & $53,4 \%$ \\
4 & Tekanan darah & & \\
& Hipertensi & 39 & $67,2 \%$ \\
& Tidak hipertensi & 19 & $32,8 \%$ \\
\hline
\end{tabular}

Dari hasilpenelitian di Unit rekam medik RSUD Dr. Moewardi didapatkan data dari masing-masing hemisfer sebagai berikut.

Tabel 2. Distribusi Sampel Penelitian Berdasarkan Jenis Kelamin

\begin{tabular}{lcccc}
\hline \multirow{2}{*}{ Jenis kelamin } & \multicolumn{2}{c}{ Laki-laki } & \multicolumn{2}{c}{ Perempuan } \\
\cline { 2 - 5 } & Jumlah & Presentase & Jumlah & Presentase \\
\hline Lesihemisferkiri & 15 & $25,8 \%$ & 14 & $24,1 \%$ \\
Lesihemisferkanan & 20 & $34,5 \%$ & 9 & $15,6 \%$ \\
Total & 35 & $60,3 \%$ & 23 & $39,7 \%$ \\
\hline
\end{tabular}


Tabel 3. Distribusi Sampel Penelitian Berdasarkan Usia

\begin{tabular}{lcccc}
\hline \multirow{2}{*}{ Usia } & \multicolumn{2}{c}{$\leq \mathbf{5 0}$ tahun } & \multicolumn{2}{c}{$>\mathbf{5 0}$ tahun } \\
\cline { 2 - 5 } & Jumlah & Presentase & Jumlah & Presentase \\
\hline Lesihemisferkiri & 4 & $6,9 \%$ & 25 & $43,1 \%$ \\
Lesihemisferkanan & 3 & $5,1 \%$ & 26 & $44,9 \%$ \\
Total & 7 & $12 \%$ & 51 & $88 \%$ \\
\hline
\end{tabular}

Tabel 4. Distribusi Sampel Penelitian Berdasarkan Tekanan Darah

\begin{tabular}{lcccc}
\hline \multirow{2}{*}{ Tekanan darah } & \multicolumn{2}{c}{ Tidak Hipertensi } & \multicolumn{2}{c}{ Hipertensi } \\
\cline { 2 - 5 } & Jumlah & Presentase & Jumlah & Presentase \\
\hline Lesihemisferkiri & 7 & $12,1 \%$ & 22 & $38 \%$ \\
Lesihemisferkanan & 12 & $20,7 \%$ & 17 & $29,2 \%$ \\
Jumlah & 19 & $32,8 \%$ & 39 & $67,2 \%$ \\
\hline
\end{tabular}

Tabel 5. Distribusi Sampel Penelitian Berdasarkan Gula Darah Sewaktu

\begin{tabular}{lcccc}
\hline \multirow{2}{*}{ GDS } & \multicolumn{2}{c}{ GDS $>\mathbf{2 0 0}$} & \multicolumn{2}{c}{ GDS $<\mathbf{2 0 0}$} \\
\cline { 2 - 5 } & Jumlah & Presentase & Jumlah & Presentase \\
Lesihemisferkiri & 15 & $25,8 \%$ & 14 & $24,1 \%$ \\
Lesihemisferkanan & 16 & $27,6 \%$ & 13 & $22,5 \%$ \\
Jumlah & 31 & $53,4 \%$ & 27 & $46,6 \%$ \\
\hline
\end{tabular}

Tabel 6.Nilai NIHSS pada masing-masing lesi hemisfer

\begin{tabular}{ccccc}
\hline & Lesi & N & Mean & Standard Deviation \\
\hline \multirow{2}{*}{ NIHSS } & Kiri & 29 & 11.9655 & 3.41721 \\
& Kanan & 29 & 7.9655 & 2.21170 \\
\hline
\end{tabular}

Dari tabel 6 didapatkan distribusi nilai NIHSS dari masing-masing hemisfer. Stroke iskemik lesi hemisfer kiri memiliki 29 sampel dengan nilai rata-rata $(11,9655)$ dan memiliki standar deviasi $(3,41721)$. Stroke iskemik lesi hemisfer kiri memiliki 29 sampel dengan nilai ratarata $(7,9655)$ dan memiliki standar deviasi $(2,2117)$.

Tabel 7. Hasil Uji Mann Whitney

\begin{tabular}{lc}
\hline & Test Statistics $^{\mathbf{a}}$ \\
\hline Mann-Whitney U & NIHSS \\
Wilcoxon W & 120.000 \\
Z & 555.000 \\
Asymp. Sig. (2-tailed) & -4.699 \\
a. Grouping Variable: Lesi & .000 \\
\hline
\end{tabular}

Dari tabel 11 dapat diketahui bahwa nilai signifikan siujiMann Whitney adalah 0,000 dibulatkan jadi 0,001 $(\mathrm{p}<0,05)$ maka dapat disimpulkan hipotesis pada penelitian ini terbuki, "Ada perbedaan tingkat deficit neurologis pada stroke iskemiklesihemisfer kiri dan kanan".

\section{PEMBAHASAN}

Distribusi data pasien berdasarkan usia menunjukkan bahwa terdapat perbedaan yang signifikan tingkat kejadian stroke pada usia $<50$ tahun dan pada usia $>50$ tahun, $88 \%$ dari seluruh sampel penelitian penderita stroke memiliki usia
$>50$ tahun. Peningkatan usia bisa menyebabkan resiko terjadinya stroke iskemik karena semakin banyak stress oksidatif dan semakin cepat pula penebalan plak aterosklerosis pada pembuluh darah otak (Coppede, 2007). 
Distribusi pasien stroke iskemik berdasarkan tekanan darah, dikelompokkan menjadi kelompok hipertensi dan tidak hipertensi.Karakteristik sampel penelitian menunjukkan bahwa sebagian besar penderita memiliki tekanan darah yang tinggi dan masuk kedalam kelompok hipertensi. Sesuai dengan penelitian sebelumnya yang dilakukan Leggeet al (2006) bahwa stroke iskemik lesi hemisfer kiri memiliki tingkat hipertensi yang lebihtinggi dibandingkan lesihemisfer kanan.

Distribusi stroke iskemik berdasarkan kadar gula darahpada penelitian ini menunjukkan bahwa lebih banyak yang mengalami hiperglikemi daripada yang tanpa hiperglikemi. Hal ini sesuai dengan yang diungkapkan Bejot dan Giroud (2010) dalam penelitiannya menyebutkan bahwa seseorang dengan keadaan hiperglikemia akan meningkatkan kejadian stroke iskemik. Senada dengan penelitian yang dilakukan Matz (2006) yang menyebutkan bahwa hiperglikemi merupakan faktor resiko yang sangat berhungan erat dengan kejadian stroke iskemik. Apabila hiperglikemi menetap secara kronik maka akan menyebabkan kerusakan pembuluh darah otak secara progresif dengan menginduksi percepatan proses atherosklerosis pembuluh darah kecil (Microangiopathy) maupun besar (Macroangiopathy) diseluruh tubuh termasuk di otak sebagai salah satu organ sasaran hiperglikemia.

Berdasarkan analisis data diatas pada Tabel 3 didapatkan hasilujiMann Whitney dengan nilai signifikansi $0,001 \quad(<0,05)$, olehkarenaitu hipotesis padapenelitianini diterima sehingga dapat disimpulkan bahwa "Terdapat perbedaan tingkat defisit neurologis pada stroke iskemik lesi hemisfer kiri dan kanan di RSUD Dr. Moewardi". Sebenarnya tidak ada ketentuan yang tepat menganai nilai signifikansi tertentu untuk menggambarkan suatu tingkat perbedaan yang sedikit atau banyak antara variabel satu dengan yang lainnya, akan tetapi untuk gambaran sederhananya dapat disimpulkan bahwa jika $\mathrm{p}$ $<0,05$ maka dapat disimpulkan bahwa terdapat perbedaan yang bermakna diatara variabel satu dengan variabel yang lainnya (Hidayat, 2011).

Penelitian ini juga sesuai dengan penelitian sebelumnya yang dilakukan oleh oleh Lyden et al (2004), Legge et al (2006), Schellinger et al (2010), dan Hedna et al (2013) yang menyebutkan bahwa terdapat perbedaan tingkat defisit neurologis antara stroke iskemik lesi hemisfer kiri dan kanan. Perbedaan ini disebabkan karen terdapat perbedaan pada lapisan tunika intima media dan kecepatan aliran darah pada arteri cerebralis hemisfer kiri sehingga seringkali terjadi perbedaan outcome antara kedua hemisfer tersebut meskipun hal ini perlu dilakukan validasi lebih lanjut. Pada beberapa penelitian yang telah dilakukan mengatakan bahwa tingkat kardioemboli sangat tinggi terjadi pada stroke iskemik lesi hemisfer kiri, telah dilakukan validasi prospektif bahwa gelembung emboli tersebut lebih sering masuk kedalam sirkulasi perdarahan hemisfer kiri dari pada hemisfer kanan.

Menurut Hedna et al (2013) terdapat perbedaan kebutuhan metabolisme pada masingmasing hemisfer, lesi hemisfer kiri memiliki metabolisme tingkat sel yang lebih tinggi sehingga memicu blood flow dihemisfer kiri lebih cepat, hal ini menyebabkan hemisfer kiri memiliki resiko yang lebih tinggi untuk mengalami penurunan fungsi dan memberikan pengaruh terhadap neuroplasticity pada kejadian stroke. Hal tersebut yang sampai saat ini menjadi dugaan penyebab terjadinya perbedaan outcome antara stroke iskemik lesi hemisfer kiri dan lesi hemisfer kanan.

Dari apa yang telah dipaparkan diatas penelitian ini memiliki beberapa kekurangan, yaitu:

1. Penelitian ini menggunakan metode Cross sectional sehingga tidak dapat menggambarkan hubungan sebab-akibat yang kuat.

2. Masing terlalu sedikit jumlah sampel yang digunakan.

3. Penelitian ini menggunakan data sekunder sehingga peneliti tidak dapat mengontrol kualitas dari pengukuran defisit neurologis untuk mendapatkan nilai dari NIHSSnya.

4. Banyak variabel perancu yang masih belum dapat dikendalikan.

\section{SIMPULAN}

Terdapat perbedaan yang bermakna tingkat defisitneurologis pada stroke iskemik lesihemisfer kiri dan kanan. 


\section{DAFTAR PUSTAKA}

Béjot, Y., Giroud, M. 2010. Stroke in diabetic patients. Diabetes \& Metabolism, 36:S84S87.

Coppede F, Migliore L. Genetic and environmental factors inneurodegenerative diseases. In : Qureshi GA, Parvez SH, editors.Oxidative stress and neurodegenerative disorders. Amsterdam : Elsevier ;2007. p. 89 - 114.

Fink, J.N., Christopher M.F., Patrick L., Kennedy L., 2008. Does Hemispheric Lateralization Influence Functional and Cardiovascular Outcomes After Stroke?. AHA Journal. 3335-40.

Gofir, A., 2009. Manajemen stroke. Yogyakarta : Pustaka cendikia press.

Goldszmidt, A.J., 2010. Stroke Essentials, Second Edition. Jones and Bartlett Publishers, LLC 40 Tall Pine Drive, Sudbury, MA 01776. 130-35

Hadi, S., 2000.Metodologi research. Yogyakarta : Andi Yogyakarta.

Hedna, V.S., Bodhit A., Ansari S., Falchook A., Stead L., Heilman K., Waters M., 2013. Hemispheric Differences in Ischemic Stroke: Is Left-Hemisphere Stroke More Common?. Jcn. 9: 97-102.

Junaidi, I., 2005. Panduan praktik Pencegahan dan Pengobatan Stroke. Jakarta : PT.Bhuana Ilmu Populer kelompok Gramedia.

Kementerian Kesehatan RI 2014. Profil Kesehatan Indonesia 2013. Jakarta : Kemenkes RI. pp: 159-63.

Legge SD., SaposnikG., Nilanon Y., Hachinski V., 2006. Neglecting the Difference Does Right or Left Matter in Stroke Outcome After Thrombolysis?. AHA Journal. 37:2066-9.
Lyden, Patrick., Claesson L., Havstad S., Ashwood T., Lu M., 2004. Factor Analysis of the Nation Institutes of Health Stroke Scale in Patient With Large Stroke. Arch Neurol. 61:1677-1680

Matz, K.,Keresztes, K., Tatschl, C., Nowotny, M., Dachenhausenm, A., Brainin, M., Toumiletho, J., 2006. Disorders of glucose metabolism in acute stroke patients: an underrecognized problem. Pubmed Diabetes Care. 29:792-97.

Misbach, J., 2011. Stroke, Aspek Diagnosis, Patofisiologi, Manajemen. Jakarta: Balai Penerbit FKUI.

Napitupulu E.Y., 2011. Pengaruh Kadar Glukosa Darah Sewaktu terhadap Keluaran Neurologik pada Pasien Stroke Iskemik Fase Akut. Universitas Diponogoro Semarang. Tesis Sp.S.

Pasiak, T.,2009. Unlimited potency of the brain :kenali dan manfaatkan sepenuhnya potensi otak anda yang tak terbatas. Jakarta :Mizanpustaka.

PERDOSSI, Kelompok Studi Stroke 2010. Stroke, Aspek Diagnosis, Patofisiologi, Manajemen. Jakarta: PERDOSSI

Schellinger, P.D., BryanR.N., CaplanL.R., DetreJ.A., EdelmanR.R., JaigobinC., KidwellC.S., MohrJ.P., SloanM., SorensenA.G., Warach S., 2010. Evidencebased guideline: The role of diffusion and perfusionMRI for the diagnosis of acute ischemic stroke. $A A N$. 75:177-185

World Health Organization 2010. Global Burden of Stroke. http://www.who.int/topics/ globalburdenofstroke/en/. Diakses pada 10 juni 2015. 